\title{
Communicating public and social services through iTV: Promoting older adults' quality of life
}

\author{
DAVID CAMPELO, TELMO SILVA, \& JORGE ABREU, University of Aveiro - \\ DIGIMEDIA
}

\begin{abstract}
As the demographic transition occurs in a global scale, dealing with the consequences of population ageing has emerged as a critical task to modern societies. This has led government entities to pay more and more attention to seniors' concerns, limitations and needs. A deep understand of old citizens, especially those unfamiliar with Internet and smartphone technologies, is also a challenge in order to enable them to fully benefit of the Information and Communication Technologies (ICTs). In the light of this issue, personalization and user-centred approaches involving older adults in all development stages may be the key for higher levels of user engagement with such ICT solutions as the interactive television (iTV) platform reported in this paper (+TV4E). The +TV4E is an on-going research project conducted at University of Aveiro, Portugal, based on a social inclusion approach, aiming to take benefit from the television viewing dynamics of senior viewers, by interweaving short and personalized adverts related to public and social services alongside regular broadcast contents. The platform is being designed with a user-centred approach featuring the integration of assistive technologies and multiple multimedia communication channels. In this paper, a system architecture to deliver the informative contents is stated and a discussion of the potential social impacts of providing such platform is presented.
\end{abstract}

\section{KEYWORDS}

interactive TV; public services; older adults; quality of life; user-centred design

\section{Introduction}

Population ageing is a global trend that in the past 50 years has led to a significant inversion of the population pyramid in developed societies. In this context, older adults' limitations and needs at physical, cognitive or psychological level, may be partially or fully resolved by technological solutions that can improve older adults' quality of life.

Often represented in the media as a phase of decline, frailty and dependence, old age is also a period where changes beyond the physical and bodily alterations are experienced. Changes in social roles may create opportunities for social participation (Cornwell, Laumann, and Schumm 2008) and personal achievement, given that, especially with retirement, these citizens have more available time for various social activities. Hence, 
seniors are increasingly seen as contributors for social development, due to their capacity to act for the good of themselves and their communities according to policies and programs which should involve all levels of society (Walker 2015).

With specific needs and more free time due to retirement, seniors tend to use the TV as the primary medium of information and entertainment. A number of studies emphasize the high usage and familiarity of this device in several countries. As an example, reports from the United Kingdom (Ofcom 2015) and Brazil (SECOM 2014) show similar results: people aged 55 and over have an average daily TV viewing of 5 hours, and this time tends to increase with age. In the particular case of Portugal, TV is a rather popular communication vehicle to people of all age sectors, and in particular to the elderly, reports show that $99 \%$ consume TV content at least once a week (Martins 2016).

Though a number of solutions based on TV technologies for seniors have already been created, developing solely innovative and advanced technological solutions is not enough. Rather, it is necessary to develop solutions that overcome the usual drawbacks of solutions already available for older adults. At this point, participatory techniques are valuable tools for achieving higher acceptance levels of technological solutions due to their main focus on end-users' limitations and needs (Newell 2003). The personalized and customized presentation of iTV services, interfaces and contents, can be achieved by User-Centred Design (Abras, Maloney-Krichmar, and Preece 2004) strategies, which involve potential end-users in all development stages. The collaboration with these users, especially during the preliminary, modelling and validation phases, enables greater involvement and greater compliance with user requirements.

In this context, given the difficulty of access to information regarding public services and recurrent scenario of info-exclusion in older adults, the +TV4E is an on-going project which aims to develop and evaluate a platform for delivering and presenting personalized informative content regarding public and social services tailored for the Portuguese older adults through iTV. These contents will be inserted along the linear TV broadcasted transmission to be presented according to short interruptions, which may be turned down or re-scheduled by users. These pieces of highly valued informative content (e.g. bulletin health services, discounts on medications, community meetings notifications, called for voting on participatory budgets, etc.) will be tailored, taking into account specific users' characteristics and interests in order to better adapt to users' expectations, needs and limitations. The +TV4E main objectives are to minimize the impact of an ageing population on developed societies and to contribute to the improvement of the quality of life of the older adults, in the form of greater autonomy, independence, social integration and empowerment. 


\section{Background}

The increase in human longevity is a cause for celebration, but it also brings up challenges and concerns for societies (Foster and Walker 2013), as demographic ageing has had great economic impacts on public health and pension systems. In several countries, public investments are being rearranged in order to comprehend the demographic and epidemiological changes observed in the last decades (Powell and Chen 2012). As an example, the European Union expenditures applied for treatment of chronic and agerelated diseases are accountable for $83 \%$ of all money spent on the health system as a whole (Wiederhold, Riva, and Graffigna 2013).

This situation led Wiederhold, Riva and Graffigna (2013) to propose structural shifts in current health systems in order to create participatory models where citizens are responsible for their own health care. Thus, treatment approaches would be based on individuals (citizen-oriented) and not based on general medical conditions or specific diseases (disease-oriented), resulting in higher engagement of citizens in their medical treatments. Wiederhold and his colleagues (2013) also point out the use of positive technology as a solution to implement these approaches. The concept of positive technology (Riva et al. 2012) focuses on the use of technology to improve the personal experience through strategies to motivate and engage users by enabling the expansion of public policies beyond traditional approaches. This concept is commonly applied by interactive TV services targeted at older adults, which, in turn, are covered in the next section.

\section{Public services}

The term 'public service' concerns any activity assigned by law to the State, performed by the government itself or through its representatives, in order to meet collective social needs (Di Pietro 1999). Thus, a public service consists of a set of actions and obligations delegated to public or private entities to fulfil collective interests and general welfare. Common roles of public services include promoting collective values, guaranteeing strategic security needs of citizens and providing health and education.

Governments have been using modern communication channels to spread their actions and to stay close to citizens as much as possible. Whether through social networking posts, promotional videos uploaded to YouTube, institutional websites and emails, or even advertisements on TV, the amount of published information related to government functions (e.g. information regarding health campaigns, calls for votes on participatory budgets, law changes notifications, etc.) has been grown enormously in the last twenty years. Many citizens, however, are not yet reached by this type of informative content, as they usually demand direct searches or previous registration with the communication channels. When considering older adults as a target audience, this informative content has limited reach, given that this public is often info-excluded (Amaro and Gil 2011). 
In addition, broadcast media options, such as traditional linear TV or broadcast radio channels may be an alternative to reach older adult population as a whole, without requiring any direct information look-up. However, audience segmentation and lack of personalization are common challenges faced in these options due to the nature of these media. Lack of personalization in content advertisement makes this broadcasted approach less efficient and too expensive. Thus, using interactive TV technologies to collect and process user data to fulfill customization needs may meet the challenges posed by audience segmentation.

\section{Interactive TV Services}

With the addition of interactivity mechanisms to the traditional (analog) TV, interactive TV platforms are now a consistent alternative for providing services and applications targeted at older people, given the great familiarity of this audience with the TV set. This alternative seems even more feasible when considering the high penetration of interactive TV technologies on a global scale. According to longitudinal studies in 138 countries, Global digital TV penetration may reach $98 \%$ of television households by 2021 (Digital TV Research 2016).

In this context, many iTV services designed to improve the quality of life of older adults have been created. Stojmenova et al. (2013) developed the Med-Reminder, an Interactive TV service that aims to remind people to take their medicines accurately and in time. In addition, this service provides features to call a relative or a health professional in an emergency situation. Additionally, Vital Mind (Miotto, Lessiter, and Freeman 2009) and MindGym (Gusev et al. 2015) are some examples of iTV services that aim to maintain older adult's well-being; promote physical activities, interactive exercises and cognitive training; and slow down physical and cognitive losses that come with the ageing process.

Raij and Lehto created the Caring TV (2008), an iTV service targeted at older people that aims to promote greater independence, security and confidence by keeping older people at home and undergoing community or self-administered treatment for longer and thus avoiding premature hospital admissions. For designing the Caring TV service, older adults were taken as active partners, considering several aspects of their daily lives, such as their own knowledge base, skills, values and experiences. Thus, the authors decided to design and develop the Caring TV with direct participation of older people and health professionals through rounds of interviews and focus groups.

Similar health caring functionalities are present in the ElderCare iTV service (López-deIpiña and Blanco 2011), which also employs second screens and attached devices to monitor the health status of users even when they are not in front of the TV. Second screens may be used for extending iTV platform functionalities. Thus, Miyazaki et al. (2013) created the "Senior Cloud", a service to stimulate communication among the 
older adults in Japan. In this iTV service, older adults could watch TV shows virtually together by chatting with the use of tablets and smartphones connected to the iTV platform.

The iNeighbourTV (Abreu, Almeida, and Silva 2013) is a SocialTV application (Oehlberg et al. 2006) that goes beyond the field of social relations and includes features to: (a) monitor older adults' daily activity; (b) provide weather information; (c) show medicine and medical appointment reminders; and (d) send alerts to health care professionals. In order to better characterize potential end-users, identify their needs and evaluate the usability requirements and interface, the iNeighbourTV was developed, using a participatory design methodology.

\section{Recommender systems}

In the context of the +TV4E Project, the concept of personalization goes beyond graphical user interfaces and aspects of interaction of interactive TV technology. This project aims to provide, via interactive TV, personalized informative contents based on older adults' needs, expectations and particularities. In the same way, Abreu et al. (2015) has proposed GUIDER, a second screen application for television content recommendation, which aimed at understanding and identifying the cognitive processes associated to TV content discovery based on user preferences. Considering the current context of content overload on linear TV channels, content recommendation is a valuable alternative to traditional EPGs (Electronic Program Guide) to support content discovery and effective information delivery.

The so called content recommendation systems comprise mechanisms to find suitable items from a large collection (Adomavicius and Tuzhilin 2005). The three main approaches used in these systems are: (i) based on content, in which recommendation has been previously consumed or viewed; (ii) collaborative, in which recommendation is based on content that has been previously consumed or viewed by users with similar profile; and (iii) hybrid, a mix of both content-based and collaborative.

Considering the existing content recommendation systems, Vanattenhoven and Geerts (2015) conducted a number of studies regarding the circumstances and viewing modes in home environment to understand how video and television programs are consumed at home. They mapped various contextual factors that determine the consumption of TV and video, such as users' schedules, mood, household structure, etc., to identify home viewing situations associated with each of these contextual factors. The results have led to valuable insights to existing recommender systems to enhance personalization according to home users' circumstantial aspects.

Personalization and content recommendation are key concepts for the +TV4E Project as it proposes a new television experience by transmitting personalized informative con- 
tent regarding public services based on specific attributes of older people, such as geographic location, health status, occupation, preferences in consumer TV shows, etc.

\section{The +TV4E project}

The +TV4E project aims to develop a platform to deliver information about social and public services via interactive TV in a personalized and suitable way appropriate for older people. Thus, informative contents of several types and formats, such as sounds, videos and texts, are remotely generated and managed for further transmission according to user profiles which are built up according to older adults' viewing behaviour and socio-demographic attributes.

\section{System architecture}

The +TV4E project combines the traditional broadcasted TV with personalized informative contents regarding social and public services whilst focusing on the aspects of wellbeing and user experience in order to enrich the TV viewing experience of older people. The proposed technical solution (see Fig. ) uses a client-server approach to deliver contents.

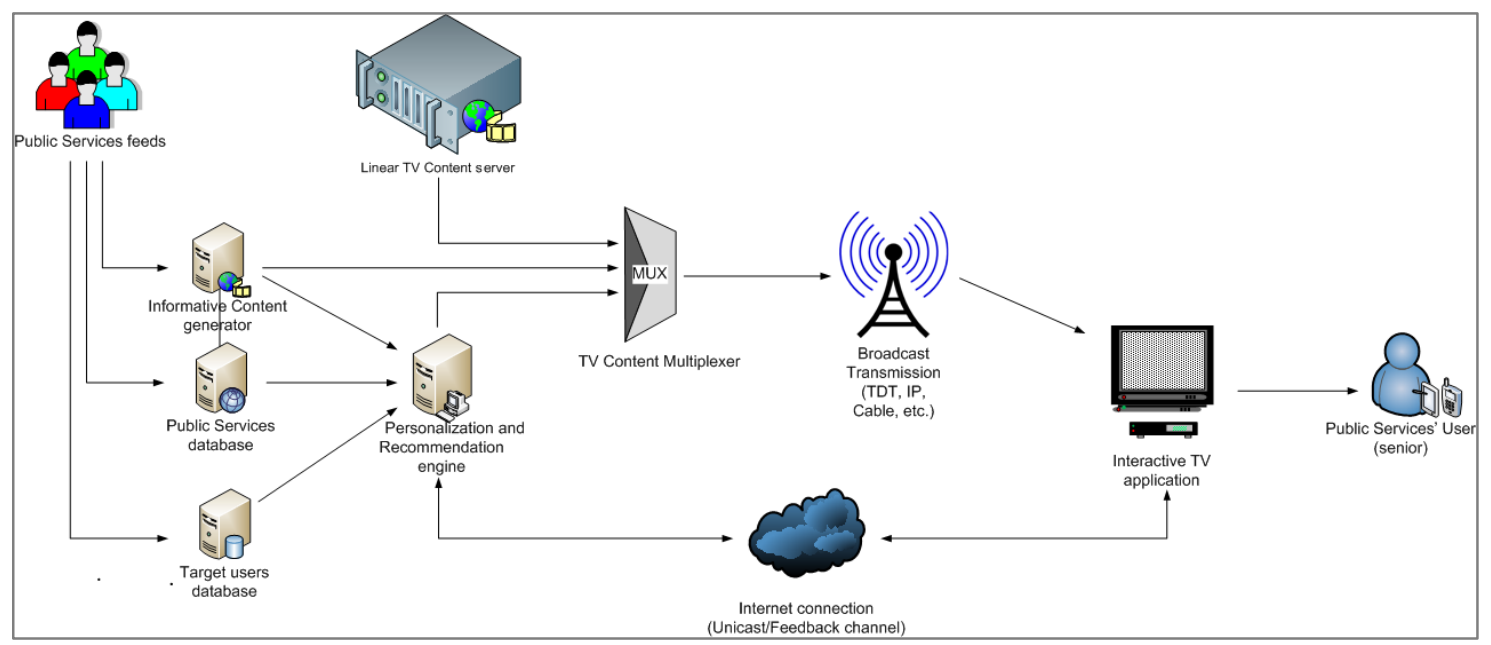

Fig. 1. +TV4E architecture.

On the client side, an Interactive TV application is designed to playback linear broadcasted TV content and informative contents in an interleaved manner. This application works in a way that the older person will receive a warning on TV screen stating that the linear transmission will be interrupted for a short time and that the informative content will be presented.

Afterwards, the transmission will be resumed and the TV viewing experience continues as usual. In addition to the information displayed on the TV set, the iTV application will enable the older adults to receive additional content on the topic through other platforms or services, for example via email or via second screens in a cross-media strategy. In 
addition, if the older person does not want to have their TV viewing experience interrupted at a given moment the informative content may be cancelled or postponed for further exhibition.

On the server side, the following components are responsible for generating informative contents; maintain user's profiles and transmitting these informative contents both via broadcast and unicast flows ${ }^{1}$. Informative Content generator functionalities include the automatic generation of informative contents regarding public and social services as well as the maintenance of their respective metadata information according to Public Services feeds. This metadata information will be matched with user profiles by content recommendation algorithms to select older adults who might be interested in the respective informative content.

The Target users' database has socio-demographic data used to build up initial user profiles while the Public Services database has governmental information organized according to a taxonomy of public and social services available for seniors (e.g. health care campaigns, tax system dates notification, etc.). Proposing a proper taxonomy of public and social services is also part of the scope of +TV4E Project.

The Personalization and recommendation engine maintains all data regarding user interactions and viewing experience obtained via Internet connection (e.g. which contents were effectively exhibited, which ones were considered useful by the older user, etc.). By cross-referencing socio demographic information retrieved from the Target users database and governmental information retrieved from Public services database with data regarding user interactions and viewing experience, a characterization of target users will be processed, and users will be grouped and classified according to interests regarding social and public services, creating consistent user profiles. Based on these user profiles, the Personalization and recommendation engine will apply content recommendation algorithms for selecting which informative contents are suitable for each older person.

The TV Content multiplexer is responsible for merging linear TV content provided by the Linear TV Content server with informative contents selected for Broadcast transmission when this informative content is to be delivered to all older adults. On the other hand, if this informative content is suitable for a subset of users, an Internet connection will be used as a Unicast channel.

\footnotetext{
${ }^{1}$ In a Unicast transmission, information is addressed from a sender to a recipient in a point-to-point connection. On the other hand, in a Broadcast transmission information is addressed from a sender to all recipients of the network in a process by which this information is transmitted to many receivers at the same time.
} 


\section{Usage scenarios}

The target audience of this project is Portuguese older population. This population is often very dependent on caregivers and has low literacy levels (Carrilho and Gonçalves 2004), which hinders their access to information related with public and social services. Moreover, having access to these kinds of services may be an even harder task due to physiological and cognitive limitations associated with the ageing process. The use of information and communication technologies by older adults may assist with some improvements in their quality of life, and television, particularly, has the potential to increase wellbeing and media literacy levels. For this reason, such a project offers an attractive opportunity for communicating information related to social and public services to seniors.

The +TV4E project consists of a technological development study with an enormous scientific potential. In Portugal, there is an increasing number of older adults, which, in turn, demands for the construction and implementation of social policy measures by taking into account their limitations and particularities. Furthermore, a lack of truly consolidated institutional practices centred on the older adults, considering their social, economic and cultural background makes this demand for technological solutions even more critical. Thus, this project focuses on this demand as it presents itself as an informational and social protection tool for the older adults.

Portuguese seniors constitute the segment of population who watch more television, which turns out to be their main leisure practice. As mentioned before, 99\% of Portuguese households have television and older adults watch around 5 hours of television per day, on average (Martins 2016). Thus, television is the most valuable technological channel to deliver contents to this population segment, operating as an enabling medium of information dissemination. Therefore, TV can work as a basis for the development of an information platform about public and social services, which promotes better understanding of such services by the older population.

A simple usage scenario of the +TV4E project consists of delivering information regarding changes in the national incomes tax system (e.g. people over 66 years old become eligible for a discount by filling up a declaration form). This information can be sent to older people whilst they watch TV according to the following steps: a) On the TV screen, in a graphical overlay, a warning appears stating that an informative content will be presented shortly; b) If the user does not cancel the content exhibition (e.g. if the user does not press a remote control key configured to cancel the information content), the informative content will be presented while the main broadcasted content is paused for a few moments. c) After the informative content presentation the TV viewing experience continues and the main broadcasted content is resumed. d) Information regarding user behaviour and experience is collected and uploaded to server side. 
These functional dynamics have some similarities with the Radio Data System (RDS) ${ }^{2}$ but with some notable differences: i) in the technology support (interactive TV system) and ii) in the personalization strategy, which provides a context awareness feature to the system, since the informative contents are tailored according to user profiles.

\section{Discussion}

The present study is part of an early stage of the larger +TV4E project - a two-year action research project conducted at University of Aveiro, Portugal, which proposes a platform designed with a user-centred approach featuring the integration of assistive technologies and multiple multimedia communication channels. To achieve that, older adults are going to be recruited to take part in cycles of conceptualization, assessment and, finally, in field tests at their home environment in order to evaluate the real impacts of the +TV4E platform in the daily activities of seniors.

Defining a high-level architecture to deliver public and social services contents is a corner stone of this on-going project. The conception of this architecture enabled the authors to assess the platform implementation requirements along with the target users, which unveiled a set of concerns and problems for the upcoming cycles of implementation and validation.

Providing information to older adults is the main requirement for the platform. However, it is critical to find out the proper timing to do this, as good or bad timing may determine the openness of the users to receive the information provided. An algorithm processed by the Personalization and recommendation engine to define the most relevant moment for content delivery is under discussion. Also, the engagement of target users depends on the way the content itself is presented on TV screen. So, different approaches of interrupting the linear TV flow were envisioned for further validation along with the recruited users.

If defining when the content should be delivered is critical, select what will be presented is indispensable, imperative for the adoption of the solution. As recommender systems' performance depend heavily on the features used to characterize entities and contents, further studies will be focused on selecting a proper recommendation algorithm, categorizing older adults needs of information concerning public and social services, and defining the possible aspects to be considered by the recommendation algorithm. Contextual factors (e.g. physical condition of the user and what program is being watched during the content delivery) as well as user feedbacks (e.g. contents fully presented, classified as relevant by the users, etc.) may also be considered by the recommendation algo-

\footnotetext{
2 Radio Data System (RDS) is a standard for sending small amounts of data through conventional FM radio broadcasts. Along with the audio, small amounts of text and data are transmitted with the radio signal. The information commonly transmitted is: station institutional information, radio program information, navigational and traffic information, time and date.

(https://en.wikipedia.org/wiki/Radio Data System)
} 
rithm to strengthen the content selection. Furthermore, pre-processing techniques, training strategies, performance metrics, as well as platform's overall scalability, delays, and load aspects must be considered.

In addition, the efficiency of selected recommendation algorithm may be affected and lowered in multi-person households, as no user identification/authentication will be supported by the platform. However, considering that different persons usually watch TV in different times of the day, a multi-user profile may be applied to emulate a multiuser environment based on the different time spans of the day.

Finally, recruiting older adults from cities nearby, as well as keeping them motivated to collaborate is considered vital for the project success. Findings of later stages in the upcoming participatory design cycles are going to be reported at a later date and finally to conduct field studies with recruited older adults.

\section{Conclusion}

A series of initiatives in the research area are focused essentially on network communities development and health applications (Blackburn, Brownsell, and Hawley 2011). There is a lack of projects related to the access of social and public services to assist seniors in management of their financial, health and social dynamics. In this context, the +TV4E project aims to identify the needs of the Portuguese seniors with respect to information about public and social services and develop a platform targeted at seniors to disseminate such information.

Participatory and collaborative methods are being be performed all over the course of +TV4E project. However, since this paper reports a preliminary version of the system architecture, even before older adults have completed cycles of requirements assessment and evaluation, solutions to tackle older adults information needs, interface presentation of the Interactive TV application, and a decision for a proper algorithm for content selection are still being discussed by the authors.

Finally, this project aims to contribute to a better quality of life and wellbeing of users, in the form of greater autonomy, independence, social integration and empowerment.

\section{Acknowledgements}

The +TV4E Project is funded by the FCT (Foundation for Science and Technology) Ref.: PTDC / CVI-COM / 3206 / 2014.

The first author would like to thank the Brazilian National Council for Scientific and Technological Development (CNPq) for providing a research productivity scholarship to support his doctoral thesis development (process 204935/2014-8). 


\section{References}

Abras, Chadia, Diane Maloney-Krichmar, and Jenny Preece. 2004. "User-Centered Design." Bainbridge, W. Encyclopedia of Human-Computer Interaction. Thousand Oaks: Sage Publications 37(4): 445-56.

Abreu, Jorge Ferraz, Pedro Almeida, and Telmo Silva. 2013. "iNeighbour TV: A Social TV Application to Promote Wellness of Senior Citizens." Information Systems and Technologies for Enhancing Health and Social Care 221: 49-58.

Abreu, Jorge Ferraz, Pedro Almeida, Telmo Silva, and Rita Oliveira. 2015. "Discovering TV Contents in a Second Screen App: Perspectives from Portuguese and Brazilian Markets." Procedia Computer Science 64: 1240-47. Doi: http://dx.doi.org/10.1016/j.procs.2015.08.508

Adomavicius, G., and A. Tuzhilin. 2005. "Toward the next Generation of Recommender Systems: A Survey of the State-of-the-Art and Possible Extensions." IEEE Transactions on Knowledge and Data Engineering 17(6): 734-49. Doi: http://dx.doi.org/10.1109/TKDE.2005.99

Amaro, Fausto, and Henrique Gil. 2011. "The 'Info-(Ex/in)-Clusion' of the Elderly People: Remarks for the Present and for the Future." In ED-MEDIA 2011-World Conference on Educational Multimedia, Hypermedia \& Telecommunications, . CONF, 1024-30.

Blackburn, Steven, Simon Brownsell, and Mark S Hawley. 2011. "A Systematic Review of Digital Interactive Television Systems and Their Applications in the Health and Social Care Fields." Journal of telemedicine and telecare 17(4): 168-76. Doi: http://dx.doi.org/10.1258/jtt.2010.100610

Carrilho, Maria José, and Cristina Gonçalves. 2004. "Dinâmicas Territoriais Do Envelhecimento: Análise Exploratória Dos Resultados Dos Censos 91 E 2001." Revista de estudos demográficos 36(1): 175-91.

Cornwell, B., E. O. Laumann, and L. P. Schumm. 2008. "The Social Connectedness of Older Adults: A National Profile." American Sociological Review 73(2): 185-203. Doi: http://dx.doi.org/10.1177/000312240807300201

Digital TV Research. 2016. "Digital TV World Household Forecasts, April 2016."[online]. Available at https://www.digitaltvresearch.com/products/product?id=140. Acessed 31 May, 2015.

López-de-Ipiña, D, and S Blanco. 2011. Activity recognition in pervasive intelligent environments. ElderCare: An Interactive TV-Based Ambient Assisted Living Platform. Atlantis Press.

Martins, Carla. 2016. As Novas Dinâmicas Do Consumo Audiovisual Em Portugal 2016. Lisboa: ERC - Entidade Reguladora para a Comunicação Social.

Miotto, Andrea, Jane Lessiter, and Jonathan Freeman. 2009. "Vital Mind: An Interactive Set-Top Box Platform for Cognitive Training Applications." In 2009 Virtual 
Rehabilitation International Conference, IEEE, 207-207. Doi:http://dx.doi.org/10.1109/ICVR.2009.5174245

Miyazaki, Masaru et al. 2013. "A Social TV System for the Senior Community: Stimulating Elderly Communication Using Information and Communications Technology." In 2013 16th International Conference on Network-Based Information Systems, IEEE, 422-27.Doi: http:dx.doi.org/10.1109/NBiS.2013.68

Newell, A. 2003. "The Future for ICT." In Inclusive Design, Springer London, 566-74. Oehlberg, Lora et al. 2006. "Social TV: Designing for Distributed, Sociable Television Viewing." In Proceedings of the 4th European Conference on Interactive TV and Video - EurolTV 2006,.

Ofcom. 2015. "The Communications Market Report." [online]. Available at http://stakeholders.ofcom.org.uk/market-data-research/market-data/communicationsmarket-reports/cmr15/.Accessed 7 July, 2016.

Di Pietro, MSZ. 1999. Direito Administrativo. São Paulo: Atlas.

Raij, Katariina, and Paula Lehto. 2008. "Caring TV as a Service Design with and for Elderly People." In New Directions in Intelligent Interactive Multimedia, Studies in Computational Intelligence, eds. George A. Tsihrintzis, Maria Virvou, Robert J. Howlett, and Lakhmi C. Jain. Berlin, Heidelberg: Springer Berlin Heidelberg, 481-88. Doi: http:dx.doi.org/10.1007/978-3-540-68127-4_49

Riva, Giuseppe et al. 2012. "Positive Technology: Using Interactive Technologies to Promote Positive Functioning." Cyberpsychology, behavior and social networking 15(2): 69-77. Doi: http:dx.doi.org/ 10.1089/cyber.2011.0139

SECOM. 2014. "Pesquisa Brasileira de Mídia 2015: Hábitos de Consumo de Mídia Pela População Brasileira."[online] http://www.secom.gov.br/atuacao/pesquisa/lista-depesquisas-quantitativas-e-qualitativas-de-contratos-atuais/pesquisa-brasileira-demidia-pbm-2015.pdf_Accessed 5 May, 2016.

Stojmenova, Emilija, Matjaž Debevc, Luka Zebec, and Bojan Imperl. 2013. "Assisted Living Solutions for the Elderly through Interactive TV." Multimedia Tools and Applications 66(1): 115-29. Doi: http://dx.doi.org/10.1007/s11042-011-0972-1

Vanattenhoven, Jeroen, and David Geerts. 2015. "Contextual Aspects of Typical Viewing Situations: A New Perspective for Recommending Television and Video Content." Personal and Ubiquitous Computing 19(5-6): 761-79. Doi: http:dx.doi.org/10.1007/s00779-015-0861-0

Walker, Alan. 2015. "Active Ageing: Realising Its Potential." Australasian Journal on Ageing 34(1): 2-8. Doi: http://dx.doi.org/ 10.1111/ajag.12219

Wiederhold, Brenda K, Giuseppe Riva, and Guendalina Graffigna. 2013. "Ensuring the Best Care for Our Increasing Aging Population: Health Engagement and Positive Technology Can Help Patients Achieve a More Active Role in Future Healthcare." Cyberpsychology, behavior and social networking 16(6): 411-12. Doi: http:dx.doi.org/ 10.1089/cyber.2013.1520 
Luiz David Campelo. is a $\mathrm{PhD}$ student in Sciences and Communication Technologies at the University of Aveiro. He holds a M.Sc. in Computer Sciences by University of Ceará, Brazil.

Email: david.campelo@ua.pt

Jorge Ferraz Abreu. is an Assistant Professor at the University of Aveiro (of the course of New Communication Technologies, of the Master in Multimedia Communication and the doctorate in information and communication in digital platforms). $\mathrm{He}$ received his $\mathrm{PhD}$ in Communication Sciences and Technologies and obtained his MSc in Electronic and Telecommunication from the University of Aveiro, Portugal. His research interests include the mechanism of presence/absence, online particiption and content sharing

Email: jfa@ua.pt

Telmo Eduardo Silva is an Assistant Professor at the Department of Communication and Arts in University of Aveiro and he is also the coordinator of the master in Multimedia Communication. He got his graduation and Master's degree in Electronic, Telecommunication and Informatics by the University of Aveiro, Portugal and a $\mathrm{PhD}$ in Information and Communication in Digital Platforms by the University of Aveiro and University of Porto. His research interests are: Design, development and evaluation of iTV services; Computer networks; Web applications based on Content Management Systems.

Email: tsilva@ua.pt 